\title{
Utilization of High Acidity Non-Food Oils from Palm Oil Mill for Biofuel Applications
}

\author{
Ichsan ${ }^{a}$ and Muda Juliandab
}

\author{
a Managing Director, PT. Maris Sustainable Indonesia, Jakarta, Indonesia \\ b Director of Engineering, PT. STC Indonesia, Lombok, Indonesia
}

\begin{abstract}
High Fatty Acids Crude Palm Oil (HFCPO) and Palm Sludge Oil (PSO) are the by-products from Palm Oil Mills. The price of HFCPO and PSO are sufficiently lower than the official price quotation of Crude Palm Oil (CPO). On the other hand, both byproducts are potential sources for biofuel applications. New patented technology that integrates extraction/esterification process from the high acidity non-food oils has been introduced. This technology is a proven technology that brings economic benefits for Palm Oil Mills that could utilize high acidity non-food oils.
\end{abstract}

Keywords: $H F C P O, P S O, C P O, S V O, F A M E$

\section{Introduction}

The Indonesian Palm Oil Mills have recognized two types of palm oil by-products from their production, namely: HFCPO (High Fatty Acids Crude Palm Oil) and PSO (Palm Sludge Oil). HFCPO is a byproduct of non-food grade oil produced from loose fruit and overripe fresh fruit bunches. While PSO is a by-product of the sterilizer process, residual oil in the waste water and oil from the filter press cake or decanter sludge.

In Indonesian market, the price of HFCPO is roughly at 35\% lower than the official price quotation of CPO (Crude Palm Oil) while the price of PSO is between $50-60 \%$ of the CPO price. Both byproducts are categorized as the non-food oil and could not be consumed. However, both palm oils can be used with high economic advantage as the raw materials for the biodiesel production.
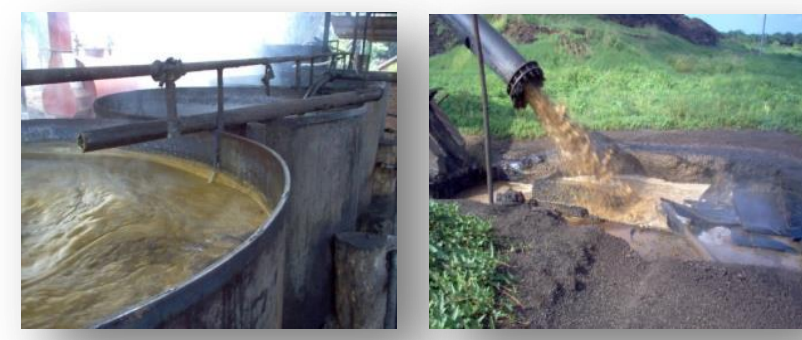

Fig. 1 HFCPO (left) and PSO (right) from Palm Oil Mill
Selective neutralization of the contained fatty acids with methanol on a solid state catalyst can be used based on a specific proprietary process. The resulting product has a very low acidity blend of methyl-ester and triglycerides that can be easily trans-esterified into finished biodiesel production along with the current state of art biodiesel production technologies that require the use of low acidity oil as a raw material. The other advantage for the final user that only a smaller quantity of methanol in producing biodiesel will be required since it already contents a percentage of methyl-ester equal to the initial percentage of fatty acids in the starting acid oil.

Table 1

HFCPO and PSO specification

\begin{tabular}{llrc}
\hline Category & \multicolumn{1}{c}{ Procedure } & Minimum & Maximum \\
\hline $\begin{array}{l}\text { 1. FFA (\% weight): } \\
\text { HFCPO }\end{array}$ & ISO 660 & & \\
PSO & & 20 & 30 \\
& & 0 & 100 \\
& D96 \& D1796 & 0 & 2 \\
& & & \\
& D5630 & 0 & 1 \\
& D5853 / & N/A & 66 \\
& ISO 3016 & 32 & N/A \\
& D93 & & 10,137 \\
\hline
\end{tabular}

ISSN 2413-5453 (C) 2015 The Authors.

Published by KnowledgeE Publishing Services. This is an open access article under the CC BY-NC-ND license

(http://creativecommons.org/licenses/by-nc-nd/4.0)

Peer-review under responsibility of EBTKE-CONEX 2013

DOI http://dx.doi.org/10.18502/ken.v1i1.345 


\section{Methodology}

It is possible to substitute the esterification of fatty acids contained in the acid oil, that producing a blend of triglycerides and methyl-ester, with a direct extraction process to extract the low acidity oil fraction from the acid oil without chemical reaction. By doing this, the Straight Vegetable Oil (SVO) can be obtained which can be used as a raw material for biodiesel plants or as fuel in diesel engines for electricity generation. This raw material is a result of pure physical process that can be claimed as "Green Power Production".

The acid fraction that was separated from the oily fraction by the extraction process can be converted into FAME (Fatty Acids Methyl Ester) according to the Indonesian Standard. FAME is used for blending with normal diesel to achieve "Green Diesel" with a great economic margin.

\section{Technology}

This plant integrates extraction/esterification process from the high acidity non-food oils that produces:

(1) Low acidity oil as raw material for biodiesel;

(2) Vegetable oil for power generation;

(3) FAME that derived from the separated acid fraction.

The present processing plant, that has been constructed and operated in Langsa, Aceh Province, was designed according to the first alternative product specification. The second alternative product is on progress to be realized soon. Both productions can be integrated in one plant. This makes the plant very flexible for the acid oils market and finished products.

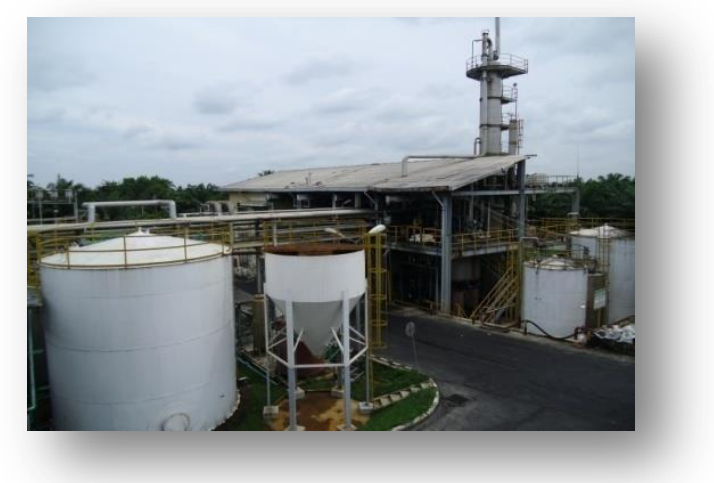

Fig. 2 Low acidity oil processing plant in Langsa, Aceh (Indonesia)
In Malaysia, a continuous pilot plant had been constructed. It consists of a pilot glass column with 4 meters high. Triglycerides from acid oils or fats have been extracted from the process. Liquid-liquid extraction is definitely more efficient than other traditional extraction methods, like: distillation or chemical reaction with glycerol. This pilot project can be visited and tested (Maurizio, 2013).

\section{Market}

The SVO and FAME are in competition with the market price of the standard CPO. They have been produced, however, from cheaper raw materials and with a lower production cost. Thus, these products become more attractive for users.

FAME has been used for blending with normal diesel in some pump stations in Indonesia (currently 2\% blend, next year 5\%). Due to the fact that the price subsidy for normal diesel has been removed by the Indonesian Government, FAME becomes more important for fuel substitution. This momentum creates a great opportunity for establishing this integrated producing plant in Indonesia.

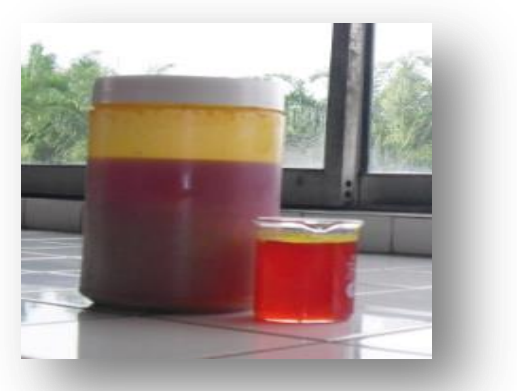

Fig. 3 Fuel product from high acidity non-food oils

\section{Conclusion}

Converting High Fatty Acids Crude Palm Oil (HFCPO) and Palm Sludge Oil (PSO) to valued products will not only create new revenue streams but also reduce our dependency to fossil fuel. It is also supporting cleaner and greener production for Palm Oil Mills. The produced "Green Power Production" and "Green Diesel" could be utilized for captive power at the Palm Oil Mills as well as for the local and international market.

A patented technology integrates extraction/ estherification process from the high acidity non-food oils that produces: low acidity oil (raw material for 
biodiesel), vegetable oil (for power generation), and FAME (i.e. biodiesel). Some plants (pilot and commercial) have been constructed based on this patented technology.

Since the operational cost for diesel power plant is increasing every year and the price subsidy for diesel transportation in Indonesia has been removed lately, this integrated plant becomes more interesting to be implemented in many places. The high demand for the produced low acidity oil and vegetable oil at the international market will also trigger more plants to be built in the next coming years.

\section{Aknowledgements}

The authors would like to thank Mr. Maurizio Germani for supporting this paper. He is the patent owner of the integrated processing plant for producing low acidity oil, vegetable oil, and FAME. He is also the owner for other international patents.

\section{References}

Germani, M. (2009) Process for the Preparation of Biodiesel, European Patent, EP 1976960 B1.

Germani, M. (2013) Biodiesel Feedstock-Straight Vegetable Oil-FAME Integrated Plant, MMG Rev 2.

Development Alternatives, Inc. (2009) Background Study: Replicable and Sustainable Use of Palm Oil Waste By-products for Employment, Creation, Resource Conservation, and Biofuel Production in Aceh, USAID Environmental Services Program (ESP) Report, Contract No. 497-M-00-05-00005-00.

High Fatty Acids Crude Palm Oil and Palm Sludge Oil Specification, Available from http://www.stcresources.com. 